\title{
Application of Genetically Engineered Acetylcholinesterases in Screen-Printed Amperometric Biosensor for Detection of Organophosphorus Insecticides
}

\author{
Angelika Galezowska, Tomasz Sikora, Georges Istamboulie ${ }^{1}$, \\ Marek Trojanowicz, Iwona Polec ${ }^{2}$, Gilvanda Silva Nunes ${ }^{3}$, \\ Thierry Noguer ${ }^{1}$ and Jean-Louis Marty ${ }^{1, *}$ \\ Department of Chemistry, University of Warsaw, Pasteura 1, 02-093 Warsaw, Poland \\ ${ }^{1}$ IMAGES EA4218, Centre de Phytopharmacie, \\ University of Perpignan Via Domitia, 66860 Perpignan, France \\ 2Institute of Industrial Organic Chemistry, Annopol 6, 03-236 Warsaw, Poland \\ ${ }^{3}$ Universidade Federal Do Maranhão, Departamento de Tecnologia Química, \\ Centro De Ciências Exatas E Tecnologia São Luís, MA, Brazil
}

(Received July 18, 2008; accepted August 29, 2008)

Key words: organophosphorus pesticide, amperometric biosensor, screen-printed electrode, acetylcholinesterase

The inhibition sensitivity of wild and mutant acetylcholinesterases (AChE) towards selected organophosphorus pesticides has been compared with enzymes immobilized in a photocured layer of polyvinylalcohol polymer (PVA-AWP) on a screen-printed graphite electrode. The investigated pesticides included the widely used malaoxon (MO), chlorfenvinphos (CFV), and chlorpyriphos-oxon (CPO). The last two insecticides are in the EC priority list of toxic compounds to be detected in water. The limits of detection (LOD) obtained with each pesticide tested were in accordance with the European regulation.

\section{Introduction}

Organophosphosphorus compounds are among the most powerful neurotoxics; they are commonly used as pesticides (insecticides) and chemical warfare agents. Even if these pesticides have a low persistence in the environment, the high toxicity of their residues disturbs ecosystems and affects humans and organisms. ${ }^{(1)}$ These compounds generally act by inhibiting acetylcholinesterase (AChE), inducing an overstimulation of the parasympathetic nervous system ${ }^{(2)}$ and affecting also the central nervous system. At very high doses, death results from paralysis of respiratory and cardiac centres. The clinical manifestations are observable a few minutes after inhalation, and one to several hours after oral uptake or cutaneous absorption.

*Corresponding author: e-mail: jlmarty@univ-perp.fr 
Early detection of organophosphorus insecticides is thus important for protecting the environment, and more particularly, water resources. Accordingly, there are growing demands for the development of field-usable devices for the sensitive and selective monitoring of these compounds. One of the contemporary trends in the analysis of pesticide residues is to develop biosensors, particularly enzymatic sensors. ${ }^{(3)}$ For that purpose, genetically engineered enzymes are increasingly employed as they show better performances such as higher sensitivity and better stability.

The use of genetically modified acetylcholinesterases has already been described for designing biosensors. It was first shown that the sensitivity of biosensors based on wild-type enzymes was dependent on the origin of the enzyme. ${ }^{(4,5)}$ On the basis of this fact, the possibilities of designing acetylcholinesterases particularly for biosensor applications have been investigated,(6) and several applications of genetically modified AChEs in electrochemical sensors have been reported..$^{(7-9)}$ The reported results indicate the possibility of predicting the effect of mutations, which may be due to the structure of the site, a deep gorge with the active serine at the bottom, and to allosteric effects between the top and the bottom of the gorge. ${ }^{(8)}$ With mutations employed so far, the greatest improvement in sensitivity was observed for the insecticide dichlorvos. ${ }^{(8,9)}$ The engineered variants of AChEs were also used in multisensors for the simultaneous detection of components of binary mixtures of insecticides with a chemometric approach using artificial neural networks. ${ }^{(10)}$

The aim of this work is to compare the sensitivities of AChE-based screenprinted amperometric biosensors to three organophosphorus insecticides, two of them (chlorpyriphos and chlorfenvinphos) are included in the European priority list of toxic substances in water (decision 2455/2001/EC). The biosensors were built using various genetically modified cholinesterases from Drosophila melanogaster (DmAChEs). The possibility of reactivating the biosensors was also tested using two nucleophilic compounds: Toxogonine and 2-PAM.

\section{Experimental}

\subsection{Reagents}

AChE from Drosophila melanogaster (Dm) was purchased from Protein Biosensor (PBS) (Toulouse, France). The enzyme was stored as dried powder at room temperature in a desiccator with stabilizers. Before use, the enzyme was separated from stabilizers by dialysis. This operation was necessary for the entrapment in PVA-AWP. Azide-unit Pendant Water-soluble Photopolymer (PVA-AWP) was provided by Toyo Gosei Kogyo Co. (Chiba, Japan).

Acetylcholinesterase from electric eel, acetylthiocholine chloride (Sigma), 5,5' -dithiobis(2-nitrobenzoic acid) (DTNB), and pyridine-2-aldoxime methochloride (2-PAM) were obtained from Sigma. Toxogonine (pyridinium, 1,1'-[oxybis (methylene)] bis [4-[(hydroxyimino)methyl]-dichloride) was purchased from Merck (Darmstadt, Germany).

The organophosphorus pesticides chlorpyriphos-oxon (CPO), chlorfenvinphos (CFV), and malaoxon (MO) were purchased from Dr. Erhenstorfer Laboratory (Germany). The 
isolated R and S enantiomers of malaoxon were synthesized at the Institute of Industrial Organic Chemistry in Warsaw. The pastes used for screen-printing, i.e., Electrodag PE-410, 423SS and 6037SS, were obtained from Acheson (Plymouth, UK). Cobaltphtalocyanine-modified carbon paste was purchased from Gwent Electronic Materials, Ltd. (Gwent, UK). A glycerophthalic paint (Astral, France) was used as an insulating layer. Hydroxyethyl cellulose (HEC) of medium viscosity was purchased from Fluka, France. Transparent PVC sheets $(200 \mathrm{~mm} \times 100 \mathrm{~mm} \times 0.5 \mathrm{~mm})$ were used as printing supports. All other reagents were of analytical grade.

\subsection{Instrumentation}

The spectrophotometric measurements were performed using a Hewlett-Packard diode array 8451A spectrophotometer. The amperometric measurements were carried out with a 641VA potentiostat (Metrohm, Switzerland), connected to a BD 40 (Kipp \& Zonen, The Netherlands) X-recorder. The $\mathrm{pH}$ was adjusted using a $\mathrm{pH}$ meter PHM 220 (Radiometer, Denmark). Enzyme separation from the stabilizers was made using Nanosep 10K Centrifugation Devices.

\subsection{Preparation of the biosensors}

Screen-printed electrodes were produced using a semi-automatic DEK 248 printing machine. The working electrode was a 4-mm-diameter disk, the auxiliary electrode was a $16 \mathrm{~mm} \times 1.5 \mathrm{~mm}$ curved line and the $\mathrm{Ag} / \mathrm{AgCl}$ pseudo-reference electrode was a 5 $\mathrm{mm} \times 1.5 \mathrm{~mm}$ straight line. An enzyme-PVA mixture was deposited manually onto the working electrode surface.

\subsection{Enzyme immobilization}

A homogeneous mixture of AChE solution and PVA-AWP in an enzyme to PVA ratio of 30:70 was prepared and $3 \mu \mathrm{L}$ of this mixture was deposited on the working electrode (WE) area. The amount of enzyme entrapped on each electrode was evaluated to be $1 \mathrm{mU}$ per electrode. The electrodes were kept under neon light for 3 hours at $+4^{\circ} \mathrm{C}$ to allow polymerization. Afterwards, the biosensors were stored for one day at $+4^{\circ} \mathrm{C}$ in a desiccator under slight vacuum.

\subsection{Determination of inhibition constant}

The activity of the free cholinesterase was photometrically evaluated by the Ellman method. ${ }^{(11)}$ The inhibition constant was measured at $30^{\circ} \mathrm{C}$ using the following procedure. Different enzyme-pesticide solutions ( $1 \mathrm{~mL}$ each) containing various pesticide concentrations were prepared. One hundred microliters of this solution was added to $900 \mu \mathrm{L}$ of solution containing $400 \mu \mathrm{L}$ of $0.1 \mathrm{M}$ phosphate buffer, $300 \mu \mathrm{L}$ of DTNB, 100 $\mu \mathrm{L}$ of water, and $100 \mu \mathrm{L}$ of substrate after 1 to 9 minutes of incubation. Each cuvette was stirred before measurement. The absorbance was recorded at $412 \mathrm{~nm}$ for $60 \mathrm{~s}$. The percentage of residual AChE activity ( $\% A r$ ) was calculated using the following relation.

$$
\% A r=100 \times \frac{\text { Slope of response after inhibition }}{\text { Slope of response prior to inhibition }}
$$


The constant $\mathrm{k}_{\mathrm{obs}}$ was determined from equation (2), as follows.

$$
\mathrm{k}_{\mathrm{obs}}(t)=-\ln \% A r
$$

The inhibition constant $\left(\mathrm{k}_{\mathrm{i}}\right)$ was calculated using GOSA software (Global Optimization by Simulated Annealing) (http://bio-log.biz).

\subsection{Measurement procedure}

Amperometric measurements were performed in magnetically stirred solutions using a $5 \mathrm{ml}$ glass cell (Fig. 1(a)). The electrodes were tested in $5 \mathrm{~mL}$ of $0.1 \mathrm{M}$ phosphate buffer at a working potential of $+100 \mathrm{mV}$ versus $\mathrm{Ag} / \mathrm{AgCl}$, which corresponds to the oxidation of thiocholine, the product of the enzymatic hydrolysis of the acetylthiocholine (ATCh) substrate in the presence of cobalt phtalocyanine as electron mediator. The intensity of the current was recorded, and after the current stabilized, the substrate was injected in the cell to a final concentration of $1 \mathrm{mM}$, and then the obtained signal was measured. Measurements were carried out until a steady-state current was reached. The cell was washed with $0.1 \mathrm{M}$ phosphate buffer ( $\mathrm{pH}$ 7) between measurements.

The determination of pesticides was carried out in a three-step procedure (Fig. 1(b)). First, the biosensor response was measured four times in the PBS. The average value of the current intensities recorded before inhibition, $I_{0}$, corresponds to the initial activity of the enzymatic biosensor. Then, the electrode was incubated for $10 \mathrm{~min}$ in a pesticide solution. Finally, the residual response of the electrode was measured. This second average value corresponds to $I_{1}$, the current after inhibition, and it is correlated to the remaining activity of the immobilised enzyme. The inhibition rate was determined

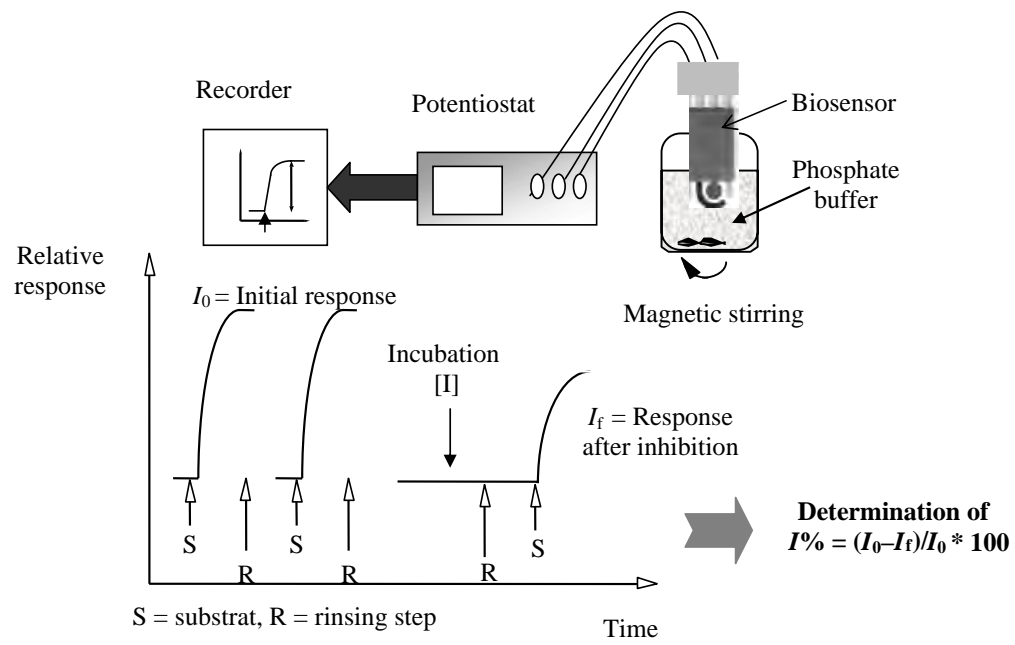

Fig. 1. Schematic representations of the sensor device (a) and measurement protocol (b). 
according to the following formula: $I(\%)=100 \times\left(I_{0}-I_{1}\right) / I_{0}$ and then related to the inhibitor concentration. The limit of detection (LOD) was calculated as the inhibitor concentration inducing a $10 \%$ decrease in the sensor response.

\section{Results and Discussion}

\subsection{Inhibition constants}

Most cholinesterase sensors are designed using acetylcholinesterases from electric eel. Human or horse acetyl- and butyryl- cholinesterases have been used also in some studies, but these enzymes generally show a low sensitivity for insecticides. We thus focused our work on the development of enzyme sensors based on wild-type or genetically modified acetylcholinesterases from Drosophila melanogaster (Dm) and we compared the results with those obtained using electric eel enzyme. Table 1 shows that the enzymes from $\mathrm{Dm}$ are much more sensitive than those from electric eel. More particularly, the B394 mutant demonstrated high inhibition constants for all the pesticides tested; the $k_{i}$ ratios between B394 and electric eel enzymes were 714, 395 and 50 for $\mathrm{CPO}, \mathrm{CFV}$ and MO, respectively. It can thus be expected that biosensors with B394 should exhibit enhanced performances in terms of sensitivity to these pesticides.

\subsection{Characteristics of the biosensor}

Various methods have already been employed for enzyme immobilization including glutaraldehyde coupling, sol-gel entrapment or affinity methods. The easiest method, giving remarkable results in terms of stability, consists in the entrapment of the enzyme in a photocrosslinkable polyvinylalcohol-based polymer: PVA-AWP. In this work, various amounts of enzyme were immobilized on the surface of the screen-printed electrodes using different ratios between enzyme solution and polymer. The largest signals were obtained using $4 \mathrm{mU}$ of enzyme and a 3:7 ratio of enzyme to PVA; in this case, the achieved sensitivity was $293 \mu \mathrm{A} / \mathrm{M}$. The results obtained with 1 and $2 \mathrm{mU}$ were very similar. It was also shown that the sensors' response was linear in a wide range of substrate concentrations. By using $1 \mathrm{mU}$ of enzyme, the linear range extended from 10 to $833 \mu \mathrm{M}$ ATC, the sensor response following the equation $I(\mathrm{nA})=292.9 \mathrm{C}(\mathrm{mM})-5.9\left(R^{2}\right.$

Table 1

Inhibition constants for various mutants of acetylcholinesterase from Drosophila melanogaster and from electric eel tested with three organophosphorus pesticides.

\begin{tabular}{ccccc}
\hline \multirow{2}{*}{ AChE origin } & Type of AChE & \multicolumn{3}{c}{ Inhibition constant $\mathrm{k}_{\mathrm{i}}, \mathrm{mmol} / \mathrm{L}$} \\
\cline { 3 - 5 } & & $\begin{array}{c}\text { Chlorpyriphos } \\
\text { oxon }\end{array}$ & Chlorfenvinphos & Malaoxon \\
\hline \multirow{2}{*}{ Drosophila } & B1 (wild type) & 990 & 4.8 & 1.0 \\
melanogaster & B6 L366F & 1200 & 7.0 & 2.5 \\
& B24 F368C & 34 & 4.1 & 0.5 \\
& B53 F368W & 68 & 6.0 & 1.0 \\
& B394 (patented) & 2500 & 55.4 & 5.0 \\
\hline Electric eel & Wild type & 3.5 & 0.14 & 0.1 \\
\hline
\end{tabular}


$=0.9994)$. To obtain the best LOD, it is favourable to reduce the amount of immobilized enzyme. In the following experimental work, $1 \mathrm{mU}$ of enzyme was immobilized on each electrode using a 3:7 ratio of enzyme to PVA.

\subsection{Operational stability, reproducibility and sensitivity of the biosensor}

The biosensors showed good operational stability, as they maintained their initial analytical signal response during eleven successive measurements. The mean of the amperometric signals for successive substrate injections using the same electrode was $244.5 \pm 9.5 \mathrm{nA}$ with RSD $=3.9 \%$ for $n=11$ assays, indicating a good reproducibility of sensor response between measurements.

Calibration curves were obtained for each pesticide by incubating the biosensors in insecticide solutions of known concentration (Fig. 2). In the case of CPO, the inhibition rate was shown to be proportional to the pesticide concentration in the range of 0.005 $0.08 \mu \mathrm{g} \mathrm{L}^{-1}$ (ppb). In contrast, calibration with CFV resulted in a wider analytical range, extending from 0.005 to $10 \mu \mathrm{g} \mathrm{L}^{-1}$. Reproducibility measurements were carried out by measuring the inhibition rate induced by $0.1 \mu \mathrm{g} \mathrm{L}^{-1} \mathrm{CPO}$, using 6 different biosensors containing $1 \mathrm{mU}$ of B394 enzyme. Under these conditions, the average inhibition rate was shown to be $40.5 \pm 7.3 \%$, with RSD $18 \%(n=6)$.

Table 2 summarizes the main characteristics of the sensors for the detection of CPO, CFV and MO. The detection limits $(I 10 \%)$ were shown to be $0.005,0.01$ and $0.02 \mu \mathrm{g}$ $\mathrm{L}^{-1}$ for $\mathrm{CFV}, \mathrm{CPO}$ and $\mathrm{MO}$, respectively. These very low values were obtained because of the very small amount of AChE B394 used (1 mU per electrode).

\subsection{Reactivation of inhibited AChE}

Attempts to reactivate the biosensor after "irreversible" inhibition by organophosphorus pesticides were carried out using a commercial preparation of Toxogonine, which is a $25 \%$ aqueous solution of [4-hydroxyimino-methylpyridine-

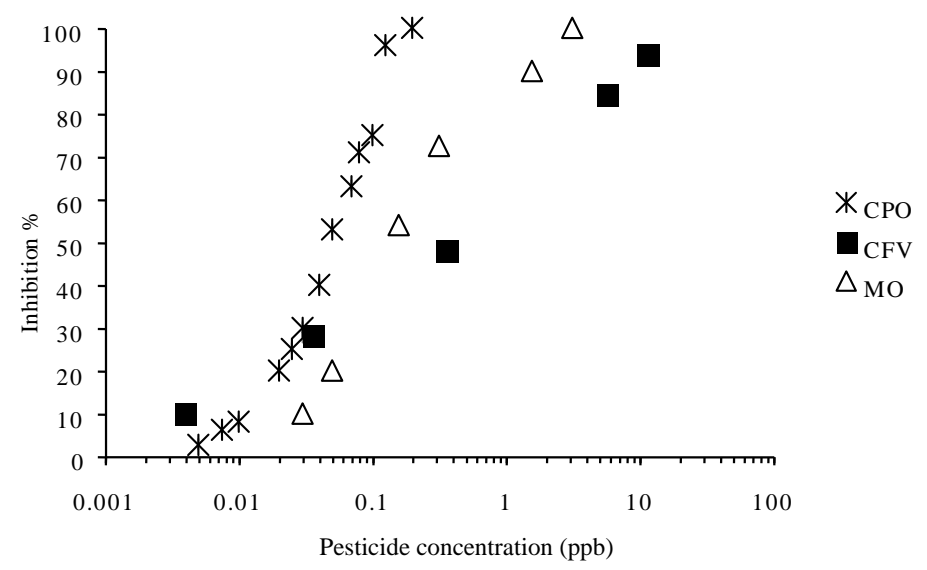

Fig. 2. Detection of chlorpyriphos-oxon (CPO), chlorfenvinphos (CFV), and malaoxon (MO) using a bi-enzymatic sensor incorporating $1 \mathrm{mU}$ of B394 AChE. 
Table 2

Characteristics of the biosensors based on B394 acetylcholinesterase (1 mU/sensor) for the detection of CPO, MO and CFV.

\begin{tabular}{ccccc}
\hline Pesticide & \multicolumn{1}{c}{ Equation } & $I_{10}(\mathrm{ppb})$ & $I_{50}(\mathrm{ppb})$ & $I_{100}(\mathrm{ppb})$ \\
\hline CPO & $I=28.867 \operatorname{Ln}(\mathrm{C})+141.51$ & 0.01 & 0.04 & 0.2 \\
MO & $I=19.719 \operatorname{Ln}(\mathrm{C})+80.729$ & 0.02 & 0.21 & 2.66 \\
CFV & $I=10.601 \operatorname{Ln}(\mathrm{C})+64.846$ & 0.005 & 0.25 & 27.6 \\
\hline
\end{tabular}

(1)-methyl]-ether dichloride. It is reported as the most powerful reactivator of organophosphorus-inhibited AChE.(12) The obtained results were compared with 2-PAM [pyridine-2-aldoxime methochloride], a widely employed reactivator of inhibited acetylcholinesterase. These studies were carried out for the inhibition of the biosensor with B394 mutant at 10 min inhibition with $10 \mathrm{ppb}$ for chlorfenvinphos and $1.5 \mathrm{ppb}$ for malaoxon, giving about $90 \%$ inhibition. One can find in the literature that $3.6 \mu \mathrm{M}$ Toxogonine decreases the inhibition of AChE from 90 to 50\%.(13) As shown in Table 3 , in the case of the SPE biosensor with immobilized AChE, a similar reduction of the inhibition degree requires about $1.4 \mathrm{mM}$ Toxogonine.

The effect of incubation time on the reaction with two reactivating reagents was examined for chlorfenvinphos and malaoxon, and it is shown in Fig. 3. The reactivation of biosensors inhibited by malaoxon occurs more easily than with CFV. Practically, a complete reactivation of the enzyme inhibited with malaoxon takes place after 60 min with the use of $10 \mathrm{mM}$ Toxogonine or $1 \mathrm{mM}$ 2-PAM. Under the same conditions, the reactivation of biosensors with CPO and CVF was only partial. Generally, we have observed a less efficient reactivation of graphite screen-printed electrodes, whereas using the same immobilization method with platinum electrodes, the reactivation was more efficient. ${ }^{(5)}$ We assume that 2-PAM and Toxogonine strongly adsorb on the surface of the graphite electrode.

\subsection{Enantioselectivity of inhibition}

The analytical and toxicological literature contains vast information on the biological role and differences in chemical interactions of stereoisomers of various groups of pesticides. ${ }^{(14)}$ This also includes organophosphorus insecticides and their interactions with AChE. A difference in insecticidal activity against houseflies and cockroaches was demonstrated for enantiomers of methamidophos and acephate;(15); $\mathrm{LD}_{50}$ values for enantiomers may differ up to 6 times. Studies on the inhibition of various cholinesterases by malaoxon enantiomers have shown that the chiral effect of inhibition significantly depends on the type of cholinesterase and its biological origin. ${ }^{(16)}$ For instance, the ratio between bimolecular inhibition constants of $\mathrm{R}$ and $\mathrm{S}$ isomers was equal to 5 for rat brain AChE and 16.2 for electric eel AChE.

In this work, the effect of $\mathrm{R}$ and $\mathrm{S}$ stereoisomers of malaoxon was investigated in the concentration range of $1-10 \mathrm{nM}$, using AChE B394 mutant immobilized on a screen-printed electrode. The recorded response was shown to be linear for the studied concentrations, with inhibition rates ranging from 10 to $80 \%$. A difference in sensitivity 
Table 3

Reactivation of a 90\%-inhibited sensor using different concentrations of Toxogonin.

\begin{tabular}{cc}
\hline Concentration of Toxogonin & Residual inhibition (\%) \\
\hline $10 \mu \mathrm{M}$ & 90 \\
$20 \mu \mathrm{M}$ & 90 \\
$0.1 \mathrm{mM}$ & 78 \\
$1 \mathrm{mM}$ & 60 \\
$1.4 \mathrm{mM}$ & 50 \\
\hline
\end{tabular}

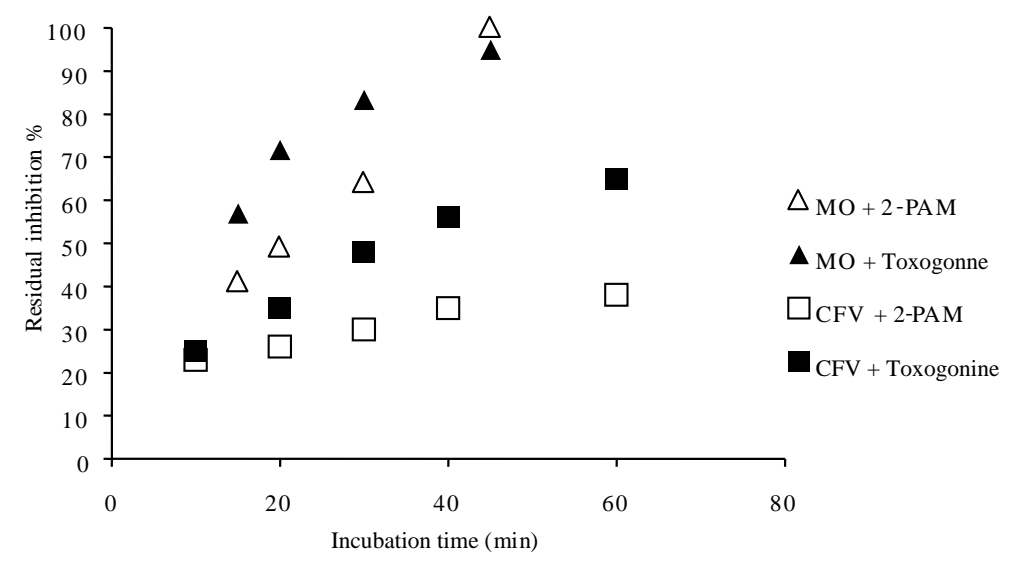

Fig. 3. Effect of incubation time on the reactivation of B394-based biosensor by 2-PAM and toxogonine.

of $4 \%$ was observed between the two malaoxon enantiomers, which is in the same order of magnitude as the measurement precision. Therefore, it was concluded that the immobilized enzyme in the described biosensor does not show any enantioselectivity of response towards malaoxon.

\subsection{Determinations in spiked wastewaters}

A biosensor based on AChE B394 was used for screening measurements in wastewater samples collected before (A) and after (B) a wastewater treatment station in Ceret, France. The measurements of inhibition at different incubation times have been carried out in raw samples, raw samples buffered with PBS, and in samples with PBS and spiked with $1 \mathrm{nM}$ chlorfenvinphos; the obtained inhibition values are shown in Fig. 4. After 20 min of inhibition, the samples with PBS showed inhibitions of 25 and $21 \%$ for A and B samples, respectively, which corresponds to insecticide concentrations close to the detection limit. For spiked samples, the determined inhibition ratios were 72 and $79 \%$ for A and B samples, respectively, which is equivalent to 105 and $135 \%$ recoveries. This preliminary data indicate the potential possibility of using the developed biosensors for the screening of trace levels of insecticides in environmental samples. 


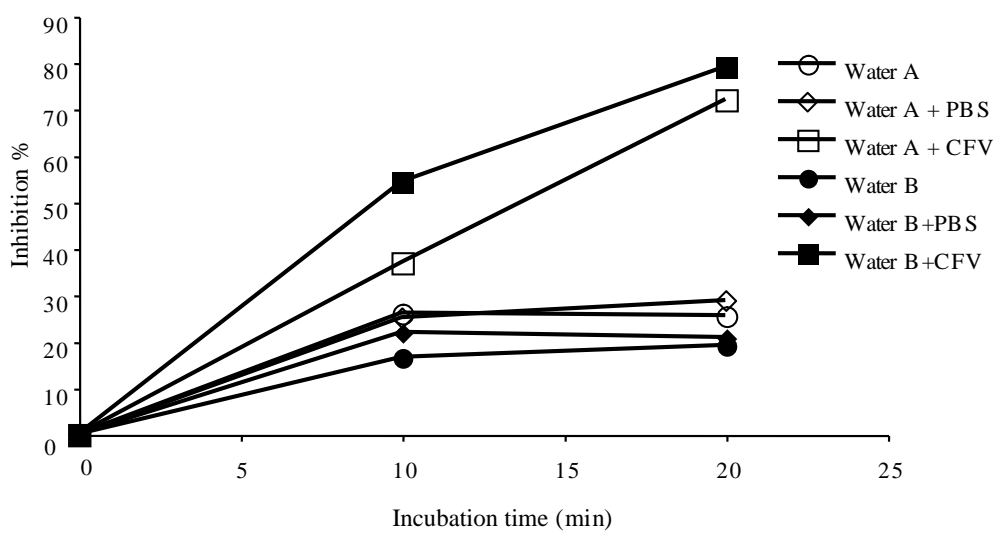

Fig. 4. Results of inhibition measurements for natural water samples using AChE B394 biosensor, without spiking and spiked with chlorfenvinphos: water before (A) and after (B) sewage treatment plant.

\section{Conclusions}

Screen-printed electrodes based on AChE have been intensively investigated. One of the problems raised by these sensors is the poor detection limit obtained for many insecticides. There is a demand for more sensitive sensors for routine applications. Because of the considerable progress in molecular biology, the sensitivity and stability of the enzymes can be enhanced. For the first time, several mutants of DmAChE have been compared for the determination of pesticides. The inhibition constant $\mathrm{k}_{\mathrm{i}}$ of the mutants for these three pesticides demonstrated clearly the interest of using genetically modified acetylcholinesterases. The LOD of the sensors was in accordance with the European regulation $\left(0.1 \mu \mathrm{g} \mathrm{L}^{-1}\right)$. Elsewhere the biosensors demonstrated a satisfactory operational stability.

Besides the commonly employed 2-PAM, the commercially available Toxogonine has been examined for the reactivation of inhibited AChEs. The assays for the reactivation of the DmAChE inhibited by chlorpyriphos-oxon were not fully successful. This phenomenon hinders the use of these biosensors in FIA devices. For this application, we are working on the development of screen-printed electrodes with acetylcholinesterase immobilized on magnetic beads, which can be replaced after each inhibition.

\section{Acknowledgements}

Angelika Galezowska and Tomasz Sikora of the University of Warsaw express their thanks to the ERASMUS program of the European Commission for granting a study leave at the University of Perpignan. 


\section{References}

1 C. Fest and K. J. Schmidt eds.: The Chemistry of Organophosphorus Pesticides, SpringerVerlag (Berlin-Heidelberg-New York, 1973) Chap. 4.

2 J. R. Reigart and J. R. Roberts eds.: Organophosphate Insecticides, Recognition and Management of Pesticide Poisonings (Washington, D.C.: Environmental Protection Agency, 1999) p. 34.

3 M. Trojanowicz: Electroanal. 14 (2002) 1311.

4 F. Villatte, V. Marcel, S. Estrada-Mondaca and D. Fournier: Biosens Bioelectron. 13 (1998) 157.

5 G. Jeanty, A. Wojciechowska, J.-L. Marty and M. Trojanowicz: Anal. Bioanal. Chem. 373 (2002) 691.

6 H. Schultze, S. Vorlova, S. Villatte, T. T. Bachmann and R. D. Schmid: Biosens. Bioelectron. 18 (2003) 201.

7 A. Avramescu, S. Andreescu, T. Noguer, C. Bala, D. Andreescu and J.-L. Marty: Anal. Bioanal. Chem. 374 (2002) 25.

8 Y. Boublik, P. Saint-Aguet, A. Lougarre, M. Arnaud, F. Villatte, S. Estrada-Mondaca and D. Fournier: Protein. Eng. 15 (2002) 43.

9 S. Sotiuropoulou, D. Fournier and N. A. Chaniotakis: Biosens. Bioelectron. 20 (2005) 2347.

10 T. T. Bachmann, B. Leca, F. Vilatte, J.-L. Marty, D. Fournier and R. D. Schmid: Biosens. Bioelectron. 15 (2000) 193.

11 G. L. Ellman, K. D. Courtney, V. Andres and R. M. Featherstone: Biochem. Pharmacol. 7 (1961) 88.

12 N. Yerushalmi and E. Cohen: Pesticide Biochem. Physiol. 72 (2002) 133.

13 G. A. Petroianu, A. Missler, K. Zuleger, C. Thyes, V. Ewald and W. H. Malecek: J. Appl. Toxicol. 24 (2004) 429.

14 J. Crosby: Pestic. Sci. 46 (1996) 11.

15 A. Miyazaki, T. Nakamura, M. Kawaradani and S. Marumo: J. Agric. Food Chem. 36 (1988) 835.

16 O. P. Rodriguez, G. W. Muth, C. E. Berkman, K. Kim and C. M. Thomspon: Bull. Environ. Contam. Toxicol. 58 (1997) 171. 